\title{
Methicillin-susceptible Staphylococcus aureus Measurement
}

National Cancer Institute

\section{Source}

National Cancer Institute. Methicillin-susceptible Staphylococcus aureus Measurement. NCI Thesaurus. Code C139111.

The determination of the amount of methicillin-susceptible Staphylococcus aureus present in a sample. 